\title{
A PRESENÇA DO DISCURSO MODERNO/COLONIAL NO CURRÍCULO E A PRODUÇÃO DE SUJEITOS
}

\author{
THE PRESENCE OF THE MODERN/COLONIAL DISCOURSE IN THE CURRICULUM AND THE PRODUCTION OF SUBJECTS
}

LA PRESENCIA DEL DISCURSO MODERNO/COLONIAL EN EL CURRÍCULO Y LA PRODUCCIÓN DE SUJETOS

\author{
TEDESCHI, Sirley Lizott 1 \\ PAVAN, Ruth²
}

\begin{abstract}
RESUMO
Neste artigo discutimos como a diferença ainda se constitui em um problema para a escola e para o currículo, como a presença de outros sujeitos que não se assemelham ao modelo idealizado pela modernidade ainda constrange, perturba e inquieta os/as professores/as. Nossa análise é fruto de pesquisa realizada - através de entrevista semiestruturada - com professores/as que atuam do sexto ao nono ano do Ensino Fundamental em uma escola pública estadual. A análise dos enunciados dos/as professores/as se aproxima da perspectiva pós-estruturalista, e entendemos que o currículo escolar ainda sofre os efeitos do discurso moderno/colonial. Capturados/as por esse discurso, os/as professores/as ainda representam a diferença a partir da mesmidade e para a mesmidade, procurando negar a pluralidade e a imprevisibilidade da alteridade.
\end{abstract}

Palavras-chave: Currículo escolar, Diferença, Identidade, Modernidade.

\section{ABSTRACT}

In this article we discuss how difference still constitutes a problem for the school and its curriculum, how the presence of other subjects who are not similar to the model idealized by modernity still embarrasses, disturbs and disquiets teachers. Our analysis results from a research project conducted - through semi-structured interviews - with teachers of the sixth to ninth grades of a public primary school. The analysis of the teachers' statements is close to the post-structuralist perspective, and we think that the school curriculum is still under the effects of the modern/colonial discourse. The teachers, captured by this discourse, still represent difference on the basis of sameness and for the sake of sameness, trying to deny plurality and the unpredictability of otherness.

Keywords: School curriculum, Difference, Identity, Modernity.

\section{RESUMEN}

En este artículo discutimos como la diferencia aún es un problema para la escuela y para el currículo; como la presencia de otros sujetos, que no se asemejan al modelo idealizado por la modernidad, aún abruma, perturba e inquieta a los/as profesores/as. El análisis es fruto de uma investigación realizada - por medio de una entrevista semiestructurada - con profesores/as del sexto al noveno año de la Enseñanza Fundamental en una escuela pública del Estado. El análisis de los enunciados de los/as profesores/as se aproxima a la perspectiva postestructuralista y entendemos que el currículo escolar aún sufre los efectos del discurso moderno/colonial. Capturados por ese discurso, los/as profesores/as aún representan la diferencia a partir de la mismidad, y, para la mismidad, procurando negar la pluralidad y la imprevisibilidad de la alteridad.

Palabras clave: Currículo escolar, Diferencia, Identidad, Modernidad.

\footnotetext{
1 Universidade Estadual de Mato Grosso do Sul - UEMS - Dourados - Mato Grosso do Sul - Brasil.

2 Universidade Católica Dom Bosco - UCDB - Campo Grande - Mato Grosso do Sul - Brasil.
} 


\section{INTRODUÇÃO}

Muitos estudos sobre o currículo apontam que a educação escolar moderna, desde seu início, exerceu papel fundamental nos processos de homogeneização das culturas, difundindo e fortalecendo uma cultura eurocêntrica com pretensões de universalidade e invisibilizando outras culturas com seus saberes, suas crenças, seus costumes (CANDAU, 2006; CARVALHO, 2005; CORAZZA; TADEU, 2003; DUSCHATZKI ; SKLIAR, 2011; ESTEBAN, 2008; GALLO, 2005; SKLIAR, 2003).

Esses autores argumentam que, ao assumir a narrativa do sujeito uno e idêntico, o currículo escolar escamoteou a produção social e histórica das identidades e diferenças, servindo como um mecanismo de exclusão e subalternização de todos aqueles sujeitos que não se assemelham ao sujeito moderno. A escola, utilizando-se dessas metanarrativas universais, contribui para a exclusão de grupos minoritários.

Em vez de grandes relatos, que buscam a unidade e silenciam a diferença, apostamos nos pequenos relatos que contem as múltiplas versões da verdade sobre a vida, sobre a sociedade, sobre o mundo; que façam ouvir a voz daqueles que foram excluídos do discurso moderno que, pela tentativa de universalização da ideia de homem branco, ocidental, heterossexual e civilizado, excluiu mulheres, negros, homossexuais, pobres, indígenas, transformando-os em monstros e sujeitos maléficos.

Deste modo, neste artigo, analisamos enunciados de professores/as - obtidos através de entrevista semiestruturada - que atuam do sexto ao nono ano do Ensino Fundamental em uma escola pública estadual, com o intuito de mostrar como a diferença ainda se constitui em um problema para a escola e para o currículo; como a presença de outros sujeitos, que não se assemelham ao modelo idealizado pela modernidade, ainda constrange, perturba e inquieta os/as professores/as. Com base nos estudos pós-estruturalistas, apresentamos, em um primeiro momento, o discurso moderno/colonial como um discurso que produziu monstros e sujeitos maléficos por meio de identificações, totalizações e unificações com o intuito de fixar a diferença e fugir da imprevisibilidade da alteridade. Em um segundo momento, apresentamos como a diferença, na escola onde realizamos a pesquisa, ainda é vista como problema escolar e curricular; como a diferença ainda é nomeada a partir do lugar do malé fico e do monstruoso. A análise mostra que o currículo escolar ainda sofre os efeitos do discurso moderno/colonial, de uma epistemologia identitária construída predominantemente na modernidade e que, por isso mesmo, ainda investe na produção do mesmo, do idêntico. Ao problematizar esta perspectiva da educação escolar e do currículo, estamos contribuindo para que os processos educativos, cada vez mais, possibilitem a produção da diferença em vez da constante reprodução do mesmo. 


\section{SOBRE TENTATIVAS DE FIXAR A DIFERENÇA - OU SOBRE O DISCURSO MODERNO/COLONIAL}

Os processos educativos são múltiplos. Os espaços escolares são espaços de multiplicidades, mesmo sob a força do projeto moderno, que "produziu totalizações, unificações, subjetivações [...] que nos embaralham a visão, nos confundem e nos enganam com um projeto único" (GALLO, 2014, p. 30). Contudo, o efeito colonizador dessas totalizações e unificações produzidas pela modernidade tem feito com que "praticamente não se converse com os outros, nem sobre outras coisas: no melhor dos casos só se conversa entre os mesmos e sobre as mesmas coisas" (SKLIAR, 2014, p. 148). Isso significa que não se deseja escutar o outro - estranho, diferente -, pois, quando o discurso moderno/colonial decidiu "que o outro é um imbecil, um mau companheiro, se irrita quando o outro finalmente mostra que não o é" (NIETZSCHE, 2006, p. 80).

$\mathrm{Na}$ história da filosofia moderna, não faltam tentativas de subalternização da alteridade por meio do discurso colonial. Aqui trazemos Kant (1993), importante pensador iluminista do século XVIII, para mostrar o caráter colonizador de sua obra. Em Observações sobre o sentimento do belo e do sublime, o autor propõe-se a analisar as diversas nações com o intuito de apontar traços que exprimam o sentimento do belo e do sublime. Ao referir-se aos italianos e franceses, destaca o sentimento do belo; ao falar dos alemães, ingleses e espanhóis, destaca o sentimento do sublime, diferentemente dos povos africanos, que, segundo ele, não possuíam esses sentimentos.

No entender de Kant (1993), a raça branca-europeia teria uma "superioridade biológica" por natureza. Por este motivo desfrutaria de um direito inerente de tutelar todos os povos que estavam fora dos padrões europeus, ou seja, que não se identificavam com os valores europeus considerados "normais". Assim, quando a Europa entrou em contato com outros povos, o objetivo foi forçá-los a assumir uma identidade semelhante à europeia. Empregou inclusive a violência, procurando fazer com que aceitassem que eram "inferiores", ditando-lhes as regras para que se tornassem "civilizados, modernos e evoluídos". Afinal, essa era a imagem que os europeus tinham de si mesmos. Essa forma de pensar e agir vinha sempre sustentada em teorias científicas e filosóficas - como, por exemplo, as teorias de Kant - que justificavam tais práticas.

Diante disso, concordamos com Santos (2002) que "a experiência social em todo o mundo é muito mais ampla e variada do que a tradição científica ou filosófica ocidental conhece e considera importante" (SANTOS, 2002, p. 238-239). Para o autor, a compreensão do mundo excede em muito a compreensão ocidental do mundo.

Também trazemos Hegel (1995), importante filósofo alemão do final do século XVIII e início do século XIX que, em sua obra Filosofia da História, ao referir-se aos nativos da América, fala que "mansidão e indiferença, humildade e submissão [...], ainda mais perante um europeu, são as principais características dos americanos do sul, e ainda custará muito até que europeus lá cheguem para incutir-Ihes uma dignidade própria" (HEGEL, 1995, p. 75). Ele continua: "[...] a inferioridade desses indivíduos, sob todos os aspectos, até mesmo o da estatura, é fácil de se reconhecer" (ibid.). 
Depois de ter feito essas considerações em sua obra, Hegel (1995) ainda diz que não vai tratar posteriormente da África porque ela não faz parte da história mundial e não tem nenhum movimento ou desenvolvimento para mostrar. Com isso, o autor retira a África da "história universal", assim como retira do povo africano a condição de humanidade.

A forma como Hegel (1995) e também Kant (1993), para citar pelo menos dois pensadores modernos, referem-se à alteridade "negra" e "latina", ou "não branca" e "não europeia", mostra a estraté gia do poder colonial de nomear a alteridade a partir de seus interesses. Para esses teóricos, a Europa cristã moderna "nada tem a aprender dos outros mundos, outras culturas. Tem um princípio em si mesma e é sua plena 'realização'” (DUSSEL, 1993, p. 21).

Referindo-se ao poder colonial da modernidade, Dussel (1993) diz que a "modernidade aparece quando a Europa se afirma como 'centro' de uma História Mundial que inaugura, e por isso a periferia é parte de sua própria definição" (DUSSEL, 1993, p. 7). O autor ainda afirma que a modernidade surge quando a Europa se confronta com o seu "outro" para exercer seu controle, "quando pode se definir como um 'ego' descobridor, conquistador, colonizador da Alteridade constitutiva da própria modernidade" (DUSSEL, 1993, p. 7). Como efeito, esse outro não foi "descoberto" como outro, e sim foi "en-coberto" como o "si-mesmo" que a Europa era desde sempre.

O colonizador impõe sua cultura ao outro, que é negado como outro e "é sujeitado, subsumido, alienado a se incorporar à Totalidade dominadora como coisa, como instrumento, como oprimido, [...] como assalariado ou como africano escravo" (DUSSEL, 1993, p. 44). Já a subjetividade do colonizador, o "eu" europeu, foi se constituindo como superior ao outro inferior, selvagem e primitivo. Desse modo, o discurso colonial da modernidade construiu muitas estratégias para controlar, disciplinar, nomear a alteridade, e o fez sempre na condição de centro. Recorreu não só à violência física contra o outro, como também à coação interna, domesticando a vida cotidiana das pessoas por intermédio de leis, costumes e valores morais. A esse respeito, Duschatzky e Skliar (2011) citam algumas estratégias de regulação e de controle do outro construídas pela modernidade:

\begin{abstract}
[...] a demonização do outro: sua transformação em sujeito ausente, quer dizer, a ausência das diferenças ao pensar a cultura; a delimitação e limitação de suas perturbações; sua invenção, para que dependa das traduções oficiais; sua permanente e perversa localização do lado externo e do lado interno dos discursos e práticas institucionais estabelecidas, vigiando permanentemente as fronteiras -, isto é, a ética perversa da inclusão/exclusão; sua oposição à totalidade de normalidade através de uma lógica binária; sua imersão e sujeição aos estereó tipos; sua fabricação e sua utilização, para assegurar e garantir as identidades fixas, centradas, homogêneas, estáveis, etc. (DUSCHATZKY; SKLIAR, 2011, p. 121).
\end{abstract}

Essa forma de posicionamento diante da alteridade advém de uma visão dicotômica e binária existem os bons, civilizados, cultos, e os maus, bárbaros, ignorantes. Quando nos sentimos pertencentes ao primeiro termo da oposição binária - os bons, civilizados, cultos -, o que precisamos fazer é invisibilizar, dominar, subjugar ou, até mesmo, eliminar o outro. Caso nos sintamos como integrantes do segundo termo da oposição - os maus, bárbaros, ignorantes -, ou aceitamos a nossa suposta maldade e nos deixamos salvar, assemelhando-nos aos bons, ou nos confrontamos de forma violenta com eles. Na lógica binária, resta à alteridade - periférica, excluída, marginalizada, que está 
nas margens, nas bordas - empenhar-se para entrar no centro e assemelhar-se aos demais, embora nunca seja igual, ou resistir ao discurso colonizador da mesmidade, da homogeneidade. Os que resistem são, segundo Skliar (2003), vigiados, castigados e controlados pelo centro, conduzidos para a periferia.

Esse modo de proceder do poder colonial produz efeitos de poder/saber sobre a alteridade mediante a produção de um conjunto de conhecimentos que, se num primeiro momento parecem pertencer somente ao colonizador - "trata-se de seu saber, de sua ciência, de sua verdade e, portanto, do conjunto de procedimentos que the são úteis para instalar e manter ad infinitum o processo de fabricação, de alterização do outro" (SKLIAR, 2003, p. 106) -, num segundo momento, transferem-se "de uma maneira muito lenta, mas violenta, também para o interior do colonizado, como se se tratasse de um próprio saber, de um conhecimento que, justamente, também Ihe resulte apropriado, Ihe seja natural" (SKLIAR, 2003, p. 106) .

Percebe-se que o discurso colonial é uma construção interessada, que intencionalmente busca fixar na mente do colonizado uma identidade específica/estereotipada que se coloca a serviço do colonizador. Apresenta "o colonizado como uma população de tipos degenerados [...] de modo a justificar a conquista e estabelecer sistemas de administração e instrução" (BHABHA, 1998, p. 111). Segundo Bhabha (1998), o estereótipo, característica fundamental do discurso colonial, "[...] não é uma simplificação porque é uma falsa representação de uma dada realidade. É uma simplificação porque é uma forma presa, fixa, de representação" (BHABHA, 1998, p. 117). A partir de estereótipos, atribui-se a determinados sujeitos um conjunto de características, tomadas como pertencentes a uma natureza humana deteriorada, com o intuito de tornar fixas e estáveis as identidades e diferenças e fugir dos perigos da imprevisibilidade da alteridade.

Nesse sentido, Carvalho (2005) destaca a urgência de questionarmos esse modo de representar a alteridade. De acordo com a autora, a escola e os/as professores/as, influenciados/as pelas "verdades" estereotipadas, podem fazer do processo educativo, em muitos casos, um processo de inferiorização do outro. Nesse sentido, o currículo escolar, o livro didático, as ações de professores/as, "podem funcionar produzindo um espaço do outro, sempre ocupado pela idéia fixa estereotipada [...] desconhecendo e desconsiderando a ambivalência das posições e dos entrelugares nos quais todos nós estamos situados" (CARVALHO, 2005, p. 95).

Hall (1997) diz que as identidade e diferenças não são fixas e estáveis; pelo contrário, são definidas historicamente e não biologicamente, "o que significa dizer que devemos pensar as identidades sociais como construídas no interior da representação, através da cultura, não fora dela" (HALL, 1997, p. 18). Identidades e diferenças são construídas na articulação entre os mais variados discursos, entre eles, o discurso pedagógico.

Mesmo que Hall (1997) nos fale sobre a construção cultural das identidades e diferenças, é grande o poder dos estereótipos no discurso pedagógico na tentativa de fixá-las, essencializá-las, naturalizá-las. No caso da escola onde desenvolvemos a pesquisa, há uma tentativa de fixar uma identidade estereotipada para os/as alunos/as de baixa renda, como se vê no que diz o professor José 
3: "aquele que tem aspecto tipo de baixa renda, que tem menos poder aquisitivo, ele é defasado em relação ao aprendizado"; ou, como diz o professor Paulo ao referir-se à mãe de uma aluna que mora na periferia: "porque você vê uma mulher dessas [...], uma visão, um nível de ignorância". Associar alunos/as pobres à defasagem de aprendizado ou a pobreza à ignorância é uma forma estereotipada que desqualifica a alteridade. No espaço escolar, esses estereótipos "aparecem como os lugares comuns do discurso, o que todo mundo diz, o que todo mundo sabe, [...] convocam mecanicamente o assentimento, quando é imediatamente compreendido, quando quase não há nem o que dizer" (LARROSA, 2011, p. 83). São tão evidentes e convincentes que dificultam as possibilidades de outros pensamentos, de outras formas de agir, julgar, avaliar; dificultam as possibilidades de pensar outras formas de educação.

Isso nos leva a pensar que o espaço escolar, em certa medida, ainda é um espaço colonial que age a partir de uma perspectiva binária - nós/outros, bons/maus, inteligentes/ignorantes, pobres/ricos e nomeia o outro a partir de estereótipos, transformando a alteridade em monstros e sujeitos indesejá veis. Essa perspectiva manifesta-se, conforme Candau (2006), sempre que

\begin{abstract}
[...] o fracasso escolar é atribuído a características sociais ou étnicas dos/as alunos/as; quando diferenciamos os tipos de escolas segundo a origem dos alunos e alunas, considerando que uns/umas são melhores que os/as outros/as, têm maior potencial; quando, como professores/as, situamo-nos diante dos/as alunos/as a partir de estereótipos e expectativas diferenciadas segundo a origem social e as características culturais dos grupos de referência; quando valorizamos exclusivamente o racional e desvalorizamos os aspectos afetivos presentes nos processos educacionais; quando privilegiamos somente a comunicação verbal, desconsiderando outras formas de comunicação humana, como a corporal, a artística, etc. (CANDAU, 2006, p. 44).
\end{abstract}

A forma estereotipada de nomear a alteridade tomando como referência a origem social, como diz Candau (2006) no fragmento acima, é expressa pelo professor Paulo ao caracterizar alunos/as de periferia que estudam na escola: "a vulgaridade, não têm compromisso, não fazem realmente nada, agressivos, são agressivos com os professores, são mais tempestuosos, mal-educados, sem bagagem nenhuma educacional, semianalfabetos".

As formações discursivas estereotipadas capturam e subjetivam o professor Paulo. A partir de estereótipos - modalidade de subjetividade -, esse professor narra, representa, nomeia os/as alunos/as de periferia que estudam na escola. Essa maneira de proceder dos/as professores/as produz efeitos de saber/poder sobre a alteridade, produz "verdades" que "não são neutras nem opacas e geram consequências na vida cotidiana desses outros" (DUSCHATZKY; SKLIAR, 2011, p. 122). Os significados estereotipados aos quais o professor Paulo recorre passam a afirmar/legitimar ou negar/excluir determinadas identidades e diferenças, tomando como referência, nesse caso, a origem social dos/as alunos/as. Essa forma de pensar, presente não somente na escola, no currículo, mas também na sociedade em geral, elimina o sujeito, restando apenas alguém que é pobre, que "não enuncia, nem denuncia, nem anuncia nada: está privado de linguagem. Revela sua contradição, sem dizer nada, está sendo produzido para testemunhar seu espaço sem falar de sua espacialidade" (ibid., p. 93).

\footnotetext{
${ }^{3}$ Para preservar o anonimato dos/as professores/as, utilizamos nomes fictícios sempre que nos referimos a eles.
} 
Negar aos sujeitos a possibilidade de dinamismo, de movimento, dificultar a construção de outros sentidos, de sentidos diferentes daqueles fixados pelo discurso hegemônico, produzir efeitos de verdade que reduzem a alteridade a tudo o que é negativo e problemático constitui uma estratégia do poder colonial para fugir das perturbações causadas pela imprevisibilidade da alteridade. O estereótipo é "uma modalidade de conhecimento e identificação que vacila entre aquilo que está sempre em um lugar já conhecido, ou melhor, esperado, e algo que deve ser ansiosamente repetido" (DUSCHATZKY; SKLIAR, 2011, p. 123). É essa forma de operar do estereótipo - fixação/repetição - que garante sua eficiência em contextos históricos distintos.

Contudo, por mais que o discurso moderno/colonial objetive que o outro seja "apagado em seu sofrimento, [...] negado em sua potencialidade de não-sofrimento, em seu acontecimento de não-misé ria, em sua potência de não-quietude" (SKLIAR, 2003, p. 92), isso não acontece de forma plena, pois o outro fala, julga e se conduz de outro modo; a imprevisibilidade da alteridade se mostra; a presença do outro/diferente emerge; a diferença resiste aos estereótipos - por isso a diferença se torna problema na escola onde desenvolvemos a pesquisa.

\section{SOBRE A PERTURBAÇÃO DA DIFERENÇA - OU SOBRE A PRESENÇA DE MONSTROS E SUJEITOS MALÉFICOS NO CURRÍCULO}

Considerando os efeitos do discurso moderno/colonial nos enunciados dos/as professores/as, expressos nas manifestações já apresentadas, podemos pensar que a relação entre diferença e "problema" pode ser estabelecida no contexto da escola onde desenvolvemos a pesquisa. Deste modo, a diferença é vista, como afirma Skliar (2003), como fonte de todo mal ou, utilizando a expressão de Foucault (2001) e de Cohen (2000), a diferença é vista como monstruosa.

Skliar (2003) destaca que a construção do outro maléfico ocorre em termos de "uma oposição em que o outro é, por força, um sempre outro, um outro permanente, uma ameaça eterna que deve ser contida e, por isso, fixada em seu estereótipo" (SKLIAR, 2003, p. 118). Ao fixar uma essência maléfica para a alteridade, a mesmidade constrói a si mesma como o oposto, constrói uma essência para si que é "regular, coerente, completa, mas, sobretudo, benigna, positiva, satisfatória, localizada em uma territorialidade oposta ao mal do outro e ao outro do mal" (SKLIAR, 2003, p. 118). A construção do sujeito maléfico é uma estratégia do pensamento identitário, predominante na modernidade, que possibilita atribuir à diferença a culpa por todos os problemas sociais - é o outro/diferente que impossibilita a sociedade de atingir sua identidade plena. A diferença, nesse caso, é portadora de todas as falhas sociais, de todos os problemas da escola.

Para o professor José, a diferença constitui um problema para a escola na medida em que afirma que a presença de outros sujeitos provocou uma defasagem no rendimento da aprendizagem. 
Houve uma defasagem em relação àquela expectativa de aluno que era CDF, o certinho que simplesmente respeitava o professor porque o professor era bravo. Aí vieram outros alunos que não foram doutrinados corporalmente, mas que também não foram doutrinados a pensar e fez com que o segundo segmento do ensino fundamental caísse. [...] aí a gente vê que aquele que tem aspecto de baixa renda, que tem menos poder aquisitivo, ele é defasado em relação ao aprendizado (professor José).

O professor José associa a diferença ao nível socioeconômico dos/as alunos/as e a relaciona com a questão do déficit de aprendizagem, ou seja, atribui o fracasso escolar às características sociais dos/as alunos/as. Ser aluno/a "pobre", nesse caso, significa ser diferente, ter dificuldade de aprendizagem, ter baixo rendimento escolar e, em consequência, ser um problema para a escola. Envolvido em contextos e discursos em que o processo escolar nem sempre atende às necessidades e particularidades de grupos subalternizados, dificultando que as múltiplas vozes sejam explicitadas e incorporadas, o professor José dobra-se ao discurso que liga o fracasso escolar à condição social dos/as alunos/as, dobra-se aos discursos que tendem a homogeneizar as identidades, subalternizando as potencialidades da diferença. No entanto, a posição que o professor José assume não se refere ao que ele é (não existe um "eu" natural, coerente, estável), mas somente ao que ele faz, e esse fazer "se configura dentro de um quadro de múltiplas negações, dentre as quais se coloca a negação da legitimidade de conhecimentos e formas de vida, formulados à margem dos limites socialmente definidos como válidos" (ESTEBAN, 2008, p. 7).

Fredric Jameson (1992), na obra O inconsciente político: a narrativa como ato socialmente simbólico, afirma que tudo aquilo que difere da mesmidade, que representa uma ameaça real e permanente para ela, é visto como problema e é caracterizado como mal.

\footnotetext{
Assim, o estranho de outra tribo, o "bárbaro" que fala uma língua incompreensível e segue costumes "exóticos", mas também a mulher, cujas diferenças biológicas estimulam fantasias de castração ou devoração, ou, em nossa própria época, o vingador de ressentimentos acumulados de uma classe ou raça oprimida ou o ser alienígena, judeu ou comunista, cujos traços aparentemente humanos escondem uma inteligência maligna e protonatural - são estes alguns dos arquétipos do Outro, com relação ao qual o importante é estabelecer não tanto o fato de que ele é temido por ser mau, mas que é mau porque é o Outro, alienígena, diferente, estranho, nebuloso e desconhecido (JAMESON, 1992, p. 115).
}

O "mal" de que fala Jameson (1992) é, no caso, tudo aquilo que ameaça a mesmidade do contexto escolar, a presença de alunos/as de periferia que chegam à escola onde ocorreu a pesquisa pelo sistema de matrícula digital disponibilizado pela Secretaria do Estado de Educação (SED). De acordo com o professor Pedro, se até então as matrículas eram realizadas na escola após entrevista com os pais e com os/as alunos/as - estratégia que possibilitava à direção um controle sobre quem frequentava a escola -, com a matrícula digital esse controle não existe mais. Por isso, a matrícula digital representa um problema para o professor Pedro: "quando vem um aluno para a escola, você não 
sabe de onde vem esse aluno, porque ele está vindo para a escola. Eu falo assim, que cada um tinha que ter um chip, você colocava lá para ver todo o histórico dele".

A matrícula digital também incomoda o professor Paulo. Segundo ele, esses/as alunos/as que chegam à escola sem nenhum controle da direção acabam "destruindo, embaralhando a cara da escola". Diz o professor:

Outra coisa que ferrou com o nosso sistema foi a matrícula digital. Antigamente, as escolas controlavam a matrícula do aluno [...]. Aqui na escola, por ser uma escola diferenciada, eles tinham o costume de entrevistar os pais. Os pais não vinham aqui simplesmente para cuidar de papel, assinar, pronto, acabou. A gente nem sabe quem é. Não, então, entrevistava os pais; aqui a escola trabalha desse jeito assim, assim. Hoje não, não existe controle nenhum, vem criança o tempo todo para cá. [...] Então, a nossa realidade, isso aqui é uma escola muito tradicional, muito forte, os alunos que estudaram aqui, os filhos vieram estudar, os netos, os bisnetos vinham estudar aqui. Quando entrou a central de matrículas, eles saíram daqui porque aquela realidade feia de escola pública de periferia veio para dentro da escola, que não tinha essa realidade, e aí estragou (professor Paulo).

Percebemos que o professor Paulo apela à tradição da escola -"isso aqui é uma escola muito tradicional' - para justificar que muitos desses/as alunos/as que chegam por meio da matrícula digital destoam do que era tradição na escola. $O$ fato de alunos/as de periferia frequentarem uma escola do centro rompe com as rotinas do local de trabalho, bem como com as relações de poder ali estabelecidas, e por isso incomoda. Isso mostra, segundo Vieira, Hypólito e Duarte (2009), como os dispositivos de controle "efetivam-se por meio de relações sociais internas à escola marcadas por discursos de apelo à tradição" (VIEIRA; HYPÓLITO; DUARTE, 2009, p. 228). Para esses autores, o efeito desses dispositivos serve para impedir/dificultar qualquer mudança nos processos de normalização, transformando em sujeitos maléficos, problemáticos e monstruosos os que não se dobram à norma.

A diferença relacionada à monstruosidade já foi destacada por Foucault (2001) em sua obra Os anormais - aula do dia 22 de janeiro de 1975. Nessa obra, o autor diz que as discrepâncias, por menores que sejam, assim como as anomalias, as pequenas diferenças, representavam o modelo do "monstro"4. O que define o monstro, para esse teórico, "é o fato de que ele constitui em sua existência mesma e em sua forma não apenas uma violação das leis da sociedade, mas uma violação das leis da

\footnotetext{
${ }^{4}$ De acordo com Foucault (2001), são diferentes as concepções de monstro humano ao longo da História. No direito romano, que serve de pano de fundo de toda a problemática do monstro, distinguem-se duas categorias: "a categoria da deformidade, da enfermidade, do defeito [...] e o monstro, o monstro propriamente dito" (FOUCAULT, 2001, p. 79). Da Idade Média ao século XVIII, o monstro é "o misto de dois reinos, o reino animal e o reino humano" (ibid.), é o homem bestial, mistura de dois indivíduos, duas espécies, dois sexos. A monstruosidade está ligada a tudo que "a desordem da lei natural vem tocar, abalar, inquietar o direito, seja o direito civil, o direito canônico ou o direito religioso" (ibid.). No Renascimento, o monstro está relacionado - na literatura, na medicina, no direito, nos textos religiosos - aos siameses, como "a representação de uma figura ambígua, de um que na verdade é dois, de dois que na verdade são um" (SKLIAR, 2003, p. 176). Na Idade Clássica, segundo Foucault (2001), foi o hermafrodita que se evidenciou como um monstro humano.
} 
natureza" (FOUCAULT, 2001, p. 69). O século XIX empenhou-se em descobrir o fundo de monstruosidade que há por trás das anomalias, dos pequenos desvios e irregularidades, e desenvolveu um conjunto de saberes/poderes - medicina, psiquiatria, pedagogia - com o intuito de corrigir essas "esquisitices, essas más conformações, esses deslizes, esses gaguejos da natureza" (FOUCAULT, 2001, p. 91). Referindo-se a Foucault, Skliar (2003) diz que o monstro, ao contradizer a lei, "em vez de receber como resposta possível outra lei, será a violência, a vontade de suprimi-lo ou, por outro lado, serão os cuidados médicos ou a argúcia da piedade as que responderão por ela" (SKLIAR, 2003, p. 175).

Também Cohen (2000) afirma que a diferença é relacionada ao "monstro", que tudo aquilo que difere radicalmente da mesmidade, que pode representar uma ameaça a ela, que não se deixa categorizar, é representado como monstruoso. Os monstros, segundo esse autor, por serem híbridos, perturbam a lógica binária - "híbridos cujos corpos externamente incoerentes resistem a tentativas para incluí-los em qualquer estruturação sistemática" (COHEN, 2000, p. 30).

Como efeito desses discursos, o professor Paulo constata que "aquela realidade das outras escolas começa a invadir a nossa realidade, a gente não está acostumado com esse tipo de coisa aqui"; o professor Pedro percebe que a diferença na escola é, muitas vezes, minimizada, reprimida, excluída e afirma que é "o próprio ambiente, os outros colegas, que fazem com que termine um pouco isso, tipo assim, ou ele (aluno/a de periferia) dança conforme a música, ou não vai se adaptar"; e o professor José constata que há, neste contexto escolar, uma necessidade de rechaçar os indígenas: "os indígenas aqui, eles são bem rechaçados, existem escolas específicas ao lado das aldeias, aqui não tem indígena".

O "monstro" referido por Cohen (2000) e por Foucault (2001) é a diferença, é o que perturba a norma, que desordena o espaço - o monstro, neste caso, é o/a aluno/a de periferia, o/a aluno/a indí gena que frequenta a escola. Ao resistirem ao enquadramento epistemológico imposto pela escola, esses/as alunos/as são vistos/as como problemáticos/as e perigosos/as. Problemáticos/as por resistirem à identidade e mostrarem a singularidade da diferença. Perigosos/as porque podem influenciar os/as outros/as alunos/as que compartilham os mesmos espaços escolares, como afirma o professor Pedro: "teve caso do aluno, do menino que se deixou influenciar pelos outros dois colegas que tinham vindo de fora [...] e então a mãe veio conversar". Isso acontece, segundo Cohen (2000), porque o monstro impede a mobilidade e delimita os espaços sociais "através dos quais os corpos privados podem se movimentar. Dar um passo fora dessa geografia oficial significa arriscar sermos atacados por alguma monstruosa patrulha de fronteira ou - o que é pior - tornarmo-nos, nós próprios, monstruosos" (COHEN, 2000, p. 41).

Queremos destacar com Skliar (2003), Foucault (2001) e Cohen (2000) que toda negatividade, monstruosidade e maldade que é atribuída à alteridade, na verdade, não é o que a constitui. Por ser a alteridade "aquilo que invade ou tenta invadir a normalidade, aquilo que desgarra ou tenta desgarrar a ordem, que nos obriga a ver e viver na ambivalência, [...] no caos, [...] na incongruência" (SKLIAR, 2003, p. 119), atribui-se a ela uma identidade maléfica essencial. Com isso, queremos dizer que 
existem outras narrativas sobre alteridade, narrativas que fazem ouvir outras vozes, outros interesses, outras vontades, outras perspectivas. Também queremos dizer que o espaço da escola onde desenvolvemos a pesquisa, embora capturado pelo discurso moderno/colonial, é um dos lugares privilegiados para construir narrativas que subvertam, como afirma Skliar (2003), "a relação maléfica entre nós e eles" (SKLIAR, 2003, p. 122).

\section{ALGUMAS CONSIDERAÇÕES}

Embora concebamos o espaço escolar como um dos lugares importantes para a construção de narrativas outras sobre a alteridade, a pesquisa mostra que esse espaço ainda sofre os efeitos do pensamento moderno/colonial, de uma epistemologia identitária que ainda nomeia a alteridade a partir do lugar do maléfico e do monstruoso. Por isso, como já dissemos, sempre que a diferença perturba a ordem escolar, a norma imposta, sempre que a diferença não se deixa assimilar na identidade, ela se torna problema. Atribui-se a ela uma série de características estereotipadas - vulgaridade, ignorância, falta de educação, falta de perspectiva, déficit de aprendizagem, agressividade, para citar algumas das manifestações dos/as professores/as. O empenho da escola e dos/as professores/as, subjetivados pelos dispositivos de normalização da modernidade, ainda consiste em corrigir os "desvios identitários", isto é, todo comportamento, atitude, gesto, pensamento, modo de ser que difere da mesmidade.

Isso mostra que ainda temos muita dificuldade de educar para a diferença, pois ela implica abrir mão dessas formas de controle e aceitar que a diferença não pode ser controlada, domesticada ou domada sem o risco de retornar à mesmidade. Gallo (2005) diz que educar para a diferença, para a singularidade, significa "lançar nossos dados sobre outras mesas, jogar outros jogos de poder, nos quais nossos papéis são outros" (GALLO, 2005, p. 223). Ou ainda, "apenas ao preço de deixarmos de ser o que somos, apenas ao preço de abandonarmos uma imagem de professor que está entre nós há milênios, podemos ser vetores de diferenciação" (GALLO, 2005, p. 223).

Talvez assim, dizem Corazza e Tadeu (2003), todos os simulacros fossem encorajados a afirmar suas "Heterogeneidades, Divergências, Descentramentos, Dessimetrias, Desigualdades Constitutivas, levando-os a positivar as próprias Potências de Fantasmas, e a fazer as suas próprias Diferenças, enquanto Semelhanças abolidas. (CORAZZA; TADEU, 2003, p. 85). Talvez assim, segundo Skliar (2014), fôssemos desafiados a escutar o desconhecido, pois não o conhecemos de antemão, e não é possível conhecê-lo jamais; seria preciso escutar o desconhecido, "porque um desconhecido traz uma voz nova, uma irrupção que pode mudar o pulso da terra, um gesto nos faz rever o já conhecido, a palavra antes ignorada" (SKLIAR, 2014, p. 150). Se escutamos a diferença, o mundo, a educação, a escola, o currículo se torna acontecimento, e o acontecimento, por ser movimento, devir, traz consigo a possibilidade de mudança nos sistemas de pensamento hegemônicos. 


\section{REFERÊNCIAS}

1. BHABHA, Homi K. O local da Cultura. 2. ed. Belo Horizonte: Editora UFMG, 1998.

2. CANDAU, Vera Maria. O/a Educador/a como agente cultural. In: LOPES, Alice Ribeiro Casimiro; MACEDO, Elizabeth Fernandes de; ALVES, Maria Palmira Carlos (Orgs.). Cultura e política de curr ículo. Araraquara/SP: Junqueira \& Martin, 2006. p. 35-52.

3. CARVALHO, Janete Magalhães. Pensando o currículo escolar a partir do outro que está em mim. In: FERRAÇO, Carlos Eduardo (Org.). Cotidiano escolar, formação de professores(as) e currículo. São Paulo: Cortez, 2005. p. 95-111.

4. COHEN, Jeffrey Jerome. A cultura dos monstros: sete teses. In: SILVA, Tomaz Tadeu da (Org.). Pedagogia dos monstros: os prazeres e os perigos da confusão de fronteiras. Belo Horizonte: Autê ntica, 2000. p. 23-60.

5. CORAZZA, Sandra; TADEU, Tomaz. Composições. Belo Horizonte: Autêntica, 2003.

6. DUSCHATZKY, Sílvia; SKLIAR, Carlos. O nome dos outros: narrando a alteridade na cultura e na educação. In: LARROSA, Jorge; SKLIAR, Carlos (Orgs.). Habitantes de Babel: políticas e poéticas da diferença. 2. ed. Belo Horizonte: Autêntica Editora, 2011. p. 119-138.

7. DUSSEL, Henrique. 1492: o encobrimento do outro: a origem do "mito da Modernidade". Petró polis/RJ: Vozes, 1993.

8. ESTEBAN, Maria Teresa. A avaliação no cotidiano escolar. In: ESTEBAN, Maria Teresa (Org.). Avaliação: uma prática em busca de novos sentidos. 5. ed. Rio e Janeiro: DP\&A, 2008. p. 7-23.

9. FOUCAULT, Michel. Os anormais. São Paulo: Martins Fontes, 2001.

10. GALLO, Silvio. Deleuze e a Educação. 2. ed. Belo Horizonte: Autêntica, 2008.

11. GALLO, Sílvio. Mínimo múltiplo comum. In: RIBETTO, Anelice. Políticas, poéticas e práticas pedag ógicas (com minúsculas). Rio de Janeiro: Lamparina, FAPERJ, 2014. p. 20-33.

12. GALLO, Sílvio. Sob o signo da diferença: em torno de uma educação para a singularidade. In: SILVEIRA, Rosa Maria Hessel (Org.). Cultura, poder e educação: um debate sobre Estudos Culturais em educação. Canoas: Ed. ULBRA, 2005. p. 213-223. 
13. HALL, Stuart. A centralidade da cultura: notas sobre as revoluções culturais do nosso tempo. Educação e Realidade, Porto Alegre, v. 22, n. 2, p. 15-46, jul./dez. 1997.

14. HEGEL, G. W. F. Filosofia da História. Brasília: Editora Universidade de Brasília, 1995.

15. JAMESON, Fredric. O inconsciente político: a narrativa como ato socialmente simbólico. São Paulo: Editora Ática, 1992.

16. KANT, Immanuel. Observações sobre o sentimento do belo e do sublime. Campinas: Papirus, 1993.

17. LARROSA, Jorge. Dar a palavra: notas sobre uma dialógica da transmissão. In: LARROSA, Jorge; SKLIAR, Carlos (Orgs.). Habitantes de Babel: políticas e poéticas da diferença. 2. ed. Belo Horizonte: Autêntica Editora, 2011. p. 281-295.

LARROSA, Jorge. Tecnologias do Eu e Educação. In.: SILVA, Tomaz Tadeu da (Org.). O sujeito da educação: estudos foucaultianos. 8 ed. Petrópolis/RJ: Vozes, 2011. p. 35-86.

19. NIETZSCHE, Friedrich. Humano, demasiado humano. São Paulo: Editora Escala, 2006.

SANTOS, Boaventura de Sousa. Para uma sociologia das ausências e uma sociologia das emergê ncias. Revista Crítica de Ciências Sociais, Coimbra: Centro de Estudos Sociais da Universidade de Coimbra, n. 63, p. 237-289, out. 2002.

21. SKLIAR, Carlos. Desobedecer a linguagem: educar. Belo Horizonte: Autêntica Editora, 2014.

22. SKLIAR, Carlos. Pedagogia (improvável) da diferença: e se o outro não estivesse aí? Rio de Janeiro: DP\&A, 2003.

23. VIEIRA, Jarbas Santos; HYPÓLITO, Álvaro Moreira; DUARTE, Bárbara Gonçalves Vaz. Dispositivos de regulação conservadora, currículo e trabalho docente. Educação e Sociedade, Campinas: Centro de Estudos Educação e Sociedade (CEDES), v. 30, n 106, p. 221-237, jan./abr. 2009.

\section{Sirley Lizott Tedeschi:}

Doutora em Educação e professora da Universidade Estadual de Mato Grosso do Sul. 


\section{Ruth Pavan:}

Doutora em Educação e professora do Programa de Pós-Graduação em Educação - Mestrado e Doutorado - da Universidade Católica Dom Bosco.

\section{Como citar este documento:}

TEDESCHI, Sirley Lizott; PAVAN, Ruth. A PRESENÇA DO DISCURSO MODERNO/COLONIAL NO CURRÍCULO E A PRODUÇÃO DE SUJEITOS. Reflexão e Ação, Santa Cruz do Sul, v. 26, n. 2, ago. 2018. ISSN 1982-9949.

Disponível em: <https://online.unisc.br/seer/index.php/reflex/article/view/11663>. Acesso em: doi:http://dx.doi.org/10.17058/rea.v26i2.11663. 